Volume 01 Nomor 01, Desember 2017

\title{
PEMIKIRAN IBNU KHALDUN TENTANG MEKANISME PASAR \& PENETAPAN HARGA
}

\author{
Indra Hidayatullah ${ }^{1}$ \\ e-mail: Indra_hidayatullah@yahoo.co.id
}

\begin{abstract}
Abstrak
Pasar merupakan salah satu penggerak roda perekonomian dalam suatu negara yang secara umum keberhasilannya bisa dilihat dari mekanisme pasar yang dijalankan. Riilnya ekonomi negara yang baik itu digerakkan oleh mekanisme pasar yang menjunjung kebebasan dan keadilan, karenanya pasar itu bebas dan tidak berpihak.Dalam sejarah ekonomi di dunia muncul beberapa ekonom Islam dan konvensional yang mengangkat tema keilmuan tentang mekanisme pasar, seperti pemikiran Ibnu Khaldun. Ibnu Khaldun mengkaji masalah-masalah ekonomi dengan jalan mengkaji sebab-sebabnya secara empiris, memperbandingkannya, untuk kemudian mengikhtisarkan hukum-hukum yang menjelaskan fenomena tersebut. Dengan demikian ia dapat disebut sebaga penggagas ekonomi ilmiah pertama.

Ibnu Khaldun hidup pada tahun 732 hingga $808 \mathrm{H}$ adalah salah seorang cendekiawan muslim yang juga turut menelurkan konsep pemikiran ekonomi Islam. Beliau yang lahir di Tunis tanggal 27 Mei 1332M mempunyai nama lengkap Abdurrahman Abu Zaid Waliuddin Ibnu Khaldun. ${ }^{2}$ Ia lebih popular dengan sebutan Ibnu Khaldun. Ibnu Khaldun mengkaji problem ekonomi masyarakat dan negara secara empiris, ia menjelaskan fenomena ekonomi secara aktual, seperti yang ia ungkapkan dalam kitab Muqaddimah-nya dalam bab 'harga-harga di kota'. Dalam bukunya Muqaddimah itu pula Ibnu Khaldun memberikan bahasan yang
\end{abstract}

\footnotetext{
${ }^{1}$ Dosen Institut Agama Islam Syarifuddin Lumajang.

2 Nur Chamid, Jejak Langkah Sejarah Pemikiran Ekonomi Islam, (Yogjakarta : Pustaka Pelajar, 2010), 246
} 
luas tentang teori nilai, pembagian kerja dan perdagangan internasional, hukum permintaan dan penawaran, konsumsi, produksi, uang, siklus perdagangan, keuangan publik dan berbagai bahasan makro ekonomi lainnya yang utamanya berkaitan dengan mekanisme pasar.

\section{Kata Kunci : Pemikiran Ibnu Khaldun, Mekanisme Pasar, Penetapan Harga}

\section{A. Pendahuluan}

Pasar, negara, individu dan masyarakat selalu menjadi topik pembahasan yang hangat dalam ilmu ekonomi. Pasar merupakan salah satu penggerak roda perekonomian dalam suatu negara yang secara umum keberhasilannya bisa dilihat dari mekanisme pasar yang dijalankan. Riilnya ekonomi negara yang baik itu digerakkan oleh mekanisme pasar yang menjunjung kebebasan dan keadilan, karenanya pasar itu bebas dan tidak berpihak. $^{3}$

Dalam penentuan harga suatu barang di suatu kota misalnya, akan tergantung oleh berkembang atau tidaknya populasi dalam daerah tersebut, bilamana populasi meningkat maka dengan sendirinya pengadaan akan barang-barang kebutuhan pokok mendapat prioritas, sehingga penawaran meningkat dan berakibat pada penurunan harga barang tersebut. Sedangkan untuk barang mewah, permintaannya akan meningkat, sejalan dengan

\footnotetext{
${ }^{3}$ Ulfa Jamilatul Farida,'Telaah Kritis Pemikiran Ekonomi Islam Terhadap Mekanisme Pasar Dalam Konteks Ekonomi Islam Kekinian' dalam La_Riba-Jurnal Ekonomi Islam, (Sleman: Universitas Islam Indonesia, 2012), 257-270
} 
perkembangan kota dan berubahnya gaya hidup. Akibatnya harga barang mewah tersebut pun menjadi naik. ${ }^{4}$

Dalam sejarah ekonomi di dunia muncul beberapa ekonom Islam dan konvensional yang mengangkat tema keilmuan tentang mekanisme pasar, seperti pemikiran Ibnu Khaldun ${ }^{5}$.

Salah seorang tokoh Muslim yang merupakan pelaku studi pemikiran ekonomi pertama yang menerapkan metode (kajian empiriskomparatif) tersebut adalah Ibnu Khaldun. Ibnu Khaldun mengkaji masalah-masalah ekonomi dengan jalan mengkaji sebab-sebabnya secara empiris, memperbandingkannya, untuk kemudian mengikhtisarkan hukumhukum yang menjelaskan fenomena tersebut. Dengan demikian ia dapat disebut sebaga penggagas ekonomi ilmiah pertama. ${ }^{6}$

Bagi Ibnu Khaldun pasar memiliki sesuatu yang istimewa yaitu kebebasan. Dalam mekanisme kerjanya pasar yang bebas akan menghasilkan harga yang adil. Pasar yang bebas akan menyuburkan lapangan kerja. Pasar yang bebas bertujuan meraih keadilan sekaligus kesejahteraan masyarakat umum. Seperti itulah bayangan pasar bebas menurut keduanya. Akan tetapi kebebasan di sini dipahami dengan definisi yang berbeda oleh keduanya.

\footnotetext{
${ }^{4}$ P3EI, Ekonomi Islam , (Jakarta : Rajawali Pers, 2012), 310-311

${ }^{5}$ Cendekiawan muslim yang hidup pada tahun $732 \mathrm{H}$ hingga $808 \mathrm{H}$, lahir di Tunis. Lihat Mohammad Abdullah Enan, Life and Work of Ibn Khaldun, (Kitab Bhavan : New Delhi, 1997), 2-3

${ }^{6}$ Muhammad Nejatullah Siddiqy, Muslim Economic Thinking, (United Kingdom :

ICRIEKAAJ and The Islamic Foundation, 1976), 261
} 
Volume 01 Nomor 01, Desember 2017

\section{B. Biografi Ibnu Khaldun}

Ibnu Khaldun dilahirkan di Tunisia pada tanggal 27 Mei $1332 ~ M,{ }^{7}$ pada awal ramadhan $732 \mathrm{H}$. Nama lengkapnya adalah Abdurrahman Abu> Zaid Waliuddin Ibnu Khaldun. Abdurrahman adalah nama kecilnya dan Abu> Zaid adalah nama panggilan keluarganya, sedangkan Waliuddin adalah gelar yang diberikan kepadanya sewaktu ia menjabat sebagai $q a>d \mid i>$ di Mesir. Selanjutnya ia lebih popular dengan sebutan Ibnu Khaldun. ${ }^{8}$

Berdasarkan silsilahnya, Ibnu Khaldun masih mempunyai hubungan darah dengan Wail bin Hajr, salah seorang sahabat Nabi SAW yang terkemuka. ${ }^{9}$

Nenek moyang Ibnu Khaldun mungkin berasal dari Hadramaut. Di Tunis keluarganya menetap setelah pindah dari Spanyol Moor. Selama empat tahun di tempat itu ia menyelesaikan Muqaddimah, tahun $1337 \mathrm{M}$. Kemudian ia pindah ke Tunis untuk menyelesaikan kitab al-I'bar (sejarah dunia) dengan perolehan bahan-bahan dari perpustakan kerajaan. ${ }^{10}$

Setelah menjalani hidup di Afrika Utara, Ibnu Khaldun berlayar ke negeri Mesir pada tahun 1383 M. Akhirnya Ibnu Khaldun meninggal dunia pada tanggal 26 Ramadhan $8 C^{\cdots \cdots} 20$ ret 1406 M dalam usia 74 tahun

\footnotetext{
${ }^{7}$ Nur Chamid, Jejak Langkah Sejarah Pemikiran Ekonomi Islam, (Jogjakarta : Pustaka Pelajar, 2010), 246

Zainab al-Khundairi, Filsafat Sejarah Ibn Khaldun. Terj. Ahmad Rafi' Usmani, (Bandung: Penerbit Pustaka, 1987), 9

9 Adiwarman Azwar Karim,Sejarah Pemikiran Ekonomi Islam, (Jakarta: Rajawali Pers, 2010), 391

${ }^{10}$ Chamid, Jejak Langkah Sejarah Pemikiran Ekonomi Islam, 247
} 
menurut perhitungan Masehi atau 76 tahun menurut perhitungan Hijriyah dan ia dimakamkan di kuburan kaum sufi ${ }^{11}$, di luar Bab al-Nahsr, Kairo.

Seperti halnya tradisi yang berkembang di masa itu, Ibnu Khaldun mengawali pelajaran dari ayahnya sendiri. Setelah itu, ia pergi berguru kepada para ulama terkemuka, seperti Abu> Abdillah Muhammad bin AlAraby Al-Has\}ayiri, Abu> Al-Abbas Ah\}mad ibnu Al-Qus\}s\}ar, Abu> Abdillah Muhammad Al-Jiyani, dan Abu> Abdillah Muhammad ibnu Ibrahi $>m$ Al-Abily, untuk mempelajari berbagai ilmu pengetahuan, seperti tata bahasa Arab, hadist, fiqih, teologi, logika, ilmu alam, matematika dan astrono

Ibnu khaldun tercatat sebagai cendekiawan yang rajin menulis, bahkan ketika memasuki usia remaja tulisan-tulisannya sudah menyebar kemana-mana. Tulisan-tulisan dan pemikiran Ibnu Khaldun terlahir karena studinya yang sangat dalam, pengamatan terhadap berbagai masyarakat yang dikenalnya dengan ilmu dan pengetahuan yang luas, serta karena ia hidup di tengah-tengah mereka dalam pengembaraannya yang luas pula. ${ }^{12}$

\section{Karir dan Karya Intelektual}

Sebagai anggota dari keluarga aristokrat, Ibnu Khaldun sudah ditakdirkan untuk menduduki jabatan tertinggi dalam administrasi negara dan mengambil bagian dalam hampir semua pertikaian politik di Afrika Utara.

\footnotetext{
${ }^{11}$ Ibid.

${ }^{12}$ Abu al-Maira, "Biografi Ibnu Khaldun"
} 
Pada tahun $1352 \mathrm{M}$, ketika masih berusia dua puluh tahun, ia sudah menjadi master of the seal / $s\} a h\} i>b$ al-'ala>mah (penyimpan tanda tangan) dan memulai karier politiknya yang berlanjut hingga 1375 M, perjalanan hidupnya beragam. Namun, baik di dalam penjara (Khaldun di penjara pada zaman Dinasti Sultan $A b u>$ Enan selama dua tahun) ${ }^{13}$ atau di istana (Khaldun hidup di lingkungan istana ketika menjabat sebagai master of the seal di Dinasti Sultan Abu> Ishaq, council of Ulama dan secretary di Dinasti Sultan Abu> Inan, secretary di Dinasti Sultan Abu> Salem, duta kerajaan Granada di Dinasty Abu> Abdillah Muhammad Ibnu $Y u>s u f)^{14}$, dalam keadaan kaya atau miskin, menjadi pelarian atau menteri, ia selalu mengambil bagian dalam peristiwa-peristiwa politik di zamannya, dan selalu tetap berhubungan dengan para ilmuwan lainnya baik dari kalangan Muslim, Kristen maupun Yahudi. Hal ini menandakan bahwa Ibnu Khaldun tidak pernah berhenti belajar. ${ }^{15}$

Ibnu Khaldun diterima dengan baik oleh raja Granada, Abu> Abdillah Muhammad Ibnu Yu>suf. Setahun setelah kedatangannya di Granada ia diangkat menjadi duta ke istana Raja Pedro El Cruel, dan ditugaskan sebagai diplomat untuk mengadakan perjanjian perdamaian antara Granada dan Sevilla. Karena prestasinya sebagai diplomat, ia diberi kedudukan yang semakin penting di Granada. Hal ini menimbulkan kecemburuan di lingkungan kerajaan, akhirnya beliau memutuskan untuk

${ }^{13}$ Abdullah Enan, Life and Work of Ibn Khaldun, 15-35

14 Ibid

${ }^{15}$ Azwar Karim,Sejarah Pemikiran Ekonomi Islam, 392-393 
kembali ke Afrika Utara. ${ }^{16}$ Di Afrika Utara Ibnu Khaldun beberapa kali mendapat tawaran jabatan politik dari para Amir (Gubernur), dan untuk ke sekian kalinya beliau berpindah tangan dari satu penguasa ke penguasa lainnya.

Setelah malang-melintang dalam kehidupan politik praktis, naluri kesarjanaannya memaksanya memasuki tahapan baru dari kehidupannya yaitu ber-khalwat. ${ }^{17}$ Dalam masa khalwat-nya dari tahun 1375-1378 M (ia jalani masa tersebut di Gal'at Ibnu Salamah-sebuah Puri di Provinsi Oran) Ibnu Khaldun mulai menulis magnum ophus-nya tentang sejarah dunia dengan Mukaddimah sebagai volume pertama. ${ }^{18}$ Dalam karyanya Muqaddimah $^{19}$ tersebut, Ibnu Khaldun mengemukakan sebuah teori model dinamika yang mempunyai pandangan jelas bagaimana faktor-faktor dinamika sosial, moral, ekonomi dan politik saling berbeda namun saling berhubungan satu dengan yang lainnya bagi kemajuan maupun kemunduran sebuah lingkungan masyarakat atau pemerintahan sebuah wilayah (negara).

Ibnu Khaldun menyelesaikan penulisan Muqaddimah-nya pada pertengahan tahun $779 \mathrm{H} / 1377 \mathrm{M}$, hanya dalam waktu lima bulan. ${ }^{20}$

16 Ibid

17 Abdullah Enan, Life and Work of Ibn Khaldun, 50-51

18 Azwar Karim,Sejarah Pemikiran Ekonomi Islam, 393. Bandingkan dengan, Abdullah Enan, Life and Work of Ibn Khaldun , 51

${ }^{19}$ Muqaddimah adalah salah satu bagian dari karya terbesar Ibnu Khaldun dalam kitab al-Ibar wa Diwan al-Mubtada' wa al-Akhbar fi Tarikh al-Arab wa al- 'Ajam wa al-Barbar. Karya ini terdiri dari tiga buah buku yang terbagi dalalm tujuh volume, yakni Mukaddimah (satu volume), al-Ibar (4 volume) dan al-Ta'rif (2 volume). Lihat Azwar Karim,Sejarah Pemikiran Ekonomi Islam, 393

${ }^{20}$ Abdullah Enan, Life and Work of Ibn Khaldun , 52 
Dalam buku Muqaddimah tersebut Ibnu Khaldun memberikan bahasan yang luas terhadap teori nilai, pembagian kerja dan perdagangan internasional, hukum permintaan dan penawaran, konsumsi, produksi, uang, siklus perdagangan, keuangan publik, dan beberapa bahasan makro ekonomi lainnya. ${ }^{21}$

Di fase selanjutnya ia habiskan 24 tahun masa hidupnya di Mesir, yaitu antara tahun 1382 sampai dengan 1406 M. Fase ini dapat dikatakan sebagai masa pengabdian Ibnu Khaldun dalam bidang akademik dan pengadilan.

\section{Pemikiran Ibnu Khaldun Tentang Mekanisme Pasar}

Mekanisme pasar adalah sebuah sistem yang menentukan terbentuknya harga, yang di dalam prosesnya dapat dipengaruhi oleh berbagai hal diantaranya adalah permintaan \& penawaran, distribusi, kebijakan pemerintah, pekerja, uang, pajak dan keamanan. ${ }^{22}$ Dalam proses mekanisme pasar tersebut diharuskan adanya asas moralitas, antara lain : persaingan yang sehat (fair play), kejujuran (honesty), keterbukaan (transparancy), dan keadilan (justice). ${ }^{23}$

Dalam penjelasan berikut ada empat faktor yang menurut Ibnu Khaldun, dapat mempengaruhi proses berjalannya mekanisme pasar.

\section{Teori Harga}

\footnotetext{
${ }^{21}$ P3EI, Ekonomi Islam, (Jakarta : Rajawali Pers, 2012), 112

${ }^{22}$ P3EI, Ekonomi Islam , (Jakarta : Rajawali Pers, 2012), 301-345

${ }^{23}$ Ulfa Jamilatul Farida,'Telaah Kritis Pemikiran Ekonomi Islam Terhadap Mekanisme Pasar Dalam Konteks Ekonomi Islam Kekinian' dalam La_Riba-Jurnal Ekonomi Islam, (Sleman: Universitas Islam Indonesia, 2012), 257-270
} 
Volume 01 Nomor 01, Desember 2017

Ibnu Khaldun dalam kitab Muqaddimah-nya menulis satu bab yang secara khusus membahas mengenai mekanisme harga, bab tersebut berjudul 'harga-harga di kota'. Dalam bab tersebut menurut Ibnu Khaldun, bila suatu kota berkembang dan populasinya pun bertambah banyak maka rakyatnya akan semakin makmur, kemudian hal tersebut akan menyebabkan terjadinya kenaikan permintaan (demand) terhadap barang-barang, dan akibatnya harga menjadi naik. Franz Rosenthal yang menerjemahkan buku Muqaddimah karya Ibnu Khaldun menjadi The Muqaddimah: An Introduction to History, ia menerjemahkan :

Then, when a city has a highly developed, abundant civilization and is full of luxuries, there is a verylarge demand for those conveniences and for having as many of them as a personcan expect in view of his situation. This results in a very great shortage of suchthings. Many will bid for them, but they will be in short supply. They will be needed for many purposes, and prosperous people used to luxuries will pay exorbitant pricesfor them, because they need them more than others. Thus, as one can see, pricescome to be high. ${ }^{24}$

Artinya : Sesungguhnya apabila sebuah kota telah makmur dan berkembang serta penuh dengan kemewahan, maka di situ akan timbul permintaan (demand) yang besar terhadap barang-barang. Tiap orang membeli barang-barang mewah itu menurut kesanggupannya. Maka barang-barang menjadi kurang. Jumlah pembeli meningkat, sementara persediaan menjadi sedikit. Sedangkan orang kaya berani membayar

${ }^{24}$ Franz Rozenthal, Ibnu Khaldun the Muqaddimah, An Introduction to History, (London : Routledge \& Kegan Paul, 1958), 283 
Volume 01 Nomor 01, Desember 2017

dengan harga tinggi untuk barang itu, sebab kebutuhan mereka makin besar. Hal ini akan menyebabkan meningkatnya harga sebagaimana anda lihat.

Seperti telah ditulis dalam kalimat diatas menurut Ibnu Khaldun dalam menentukan harga di pasar atas sebuah produksi, faktor yang sangat berpengaruh adalah permintaan dan penawaran. ${ }^{25}$ Menurutnya apabila sebuah kota berkembang dengan pesat, mengalami kemajuan dan penduduknya padat, maka persedian bahan makanan pokok melimpah. Hal ini dapat diartikan bahwa penawaran yang meningkat mengakibatkan harga bahan/barang pokok tersebut murah. Seperti ditulis dalam The Muqaddimah: An Introduction to History: "When a city is highly developed and has many inhabitants, the prices of necessary foodstuffs and corresponding items are low..." Artinya : Ketika sebuah kota yang sangat maju dan memiliki banyak penduduk, harga bahan makanan dan barang-barang yang diperlukan menjadi rendah/murah ...

Ibnu Khaldun menekankan bahwa kenaikan penawaran atau penurunan permintaan menyebabkan kenaikan harga, demikian pula sebaliknya kenaikan permintaan atau penurunan penawaran akan menyebabkan penurunan harga. ${ }^{26}$

Analisa Ibnu Khaldun tentang harga tersebut yang dirumuskan menggunakan hukum supply and demand adalah merupakan suatu rumusan yang luar biasa di zamannya, karena hal tersebut terjadi jauh

\footnotetext{
${ }^{25}$ Chamid, Jejak Langkah Sejarah Pemikiran Ekonomi Islam, 251

${ }^{26}$ P3EI, Ekonomi Islam, 310-311
} 
sebelum para ekonom konvensional seperti Adam Smith, David Ricardo dkk. merumuskan teori tersebut. Dari kalimat pertama Ibnu Khaldun di atas dijelaskan bahwa pasar adalah tempat yang menyediakan kebutuhan manusia, baik itu kebutuhan primer, sekunder maupun tertier. ${ }^{27}$

2. Teori Nilai

Menurut Ibnu Khaldun, tenaga kerja menjadi sumber yang sangat berharga. Tenaga kerja penting bagi semua akumulasi modal dan pendapatan. Sekalipun pendapatan dihasilkan dari sesuatu selain keahlian, nilai-nilai dari menghasilkan laba dan modal harus mencakup nilai tenaga kerja. Tanpa tenaga kerja hal tersebut belum diperoleh. ${ }^{28} \mathrm{Di}$ dalam The Muqaddimah: An Introduction to History Ibnu Khaldun menyatakan :

A large civilization yields large profits because of the large amount of (available) labor, which is the cause of (profit) ${ }^{29}$

It will become clear in the fifth chapter, which deals with profit and sustenance, that profit is the value realized from labor. When there is more labor, the value realized from it increases among the (people). Thus, their profit of necessity increases. The prosperity and wealth they enjoy leads them to luxury and the things that go with it, such as splendid houses and clothes, fine vessels and utensils, and the use of servants and mounts. All these (things) involve activities that require their price and skillful people must be chosen to do them and be

${ }^{27}$ Agustianto, "Pemikiran Ekonomi Ibnu Khaldun,"

${ }^{28}$ Chamid, Jejak Langkah Sejarah Pemikiran Ekonomi Islam, 253

${ }^{29}$ Rozenthal, Ibnu Khaldun the Muqaddimah, An Introduction to History, 287 
Volume 01 Nomor 01, Desember 2017

incharge of them. As a consequence, industry and the crafts thrive. The income and the expenditure of the city increase. Affluence comes to those who work and produce these things by their labor. ${ }^{30}$

Artinya : Sebuah peradaban besar menghasilkan keuntungan yang besar karena besarnya jumlah (tersedia) tenaga kerja, yang merupakan penyebab dari (keuntungan).

Ini akan menjadi jelas dalam pasal lima, yang berkaitan dengan keuntungan dan rezeki, keuntungan itu adalah nilai yang direalisasikan dari tenaga kerja. Ketika ada lebih banyak tenaga kerja, nilai yang direalisasikannya pun akan turut meningkat. Dengan demikian, keuntungan mereka turut meningkat. Kemakmuran dan kekayaan yang mereka nikmati membawa mereka kepada kemewahan dan hal-hal yang bersamaan dengan itu, seperti rumah-rumah yang indah dan pakaian, pembuluh halus dan peralatan, dan penggunaan pembantu (PRT) dan kendaraan. Semua ini (hal-hal) merupakan kegiatan yang membutuhkan harga/upah dan orang-orang terampil harus dipilih untuk melakukannya dan menjadi ongkos dari mereka. Akibatnya, dunia industri dan kerajinan berkembang. Pendapatan dan pengeluaran kota naik. Kemakmuran datang kepada mereka yang bekerja dan menghasilkan hal-hal ini dengan kerja mereka.

Demikian pula kekayaan bangsa-bangsa tidak ditentukan oleh banyaknya uang yang dimiliki oleh bangsa tersebut, tetapi ditentukan

${ }^{30}$ Ibid, 280 
oleh jumlah produksi barang dan jasa serta neraca yang sehat. Dari sana terlihat bahwa keduanya saling berkaitan. Bahwa apabila neraca pembayaran sehat, konsekuensinya adalah tingkat produksi barang yang tinggi. Sebagaimana diutarakan oleh Ibnu Khaldun dalam Mukaddimahnya :

Ibnu Khaldun adalah ilmuwan pertama dalam sejarah yang memberikan penjelasan detail tentang teori nilai buruh. Walaupun pada kenyataanya Ibnu Khaldun tak pernah menyebut nilai buruh dengan istilah teori. Meski demikian Ibnu Khaldun tetap mampu memaparkan penjelasan tentang buruh secara detail dalam bab IV buku Muqaddimah.

\section{Spesialisasi Kerja}

Manusia dalam kodratnya adalah sebagai individu yang saling membutuhkan satu sama lainnya (zoon politicon). Dalam pengertian yang lain dapat dipahami bahwa manusia adalah mahluk yang lemah dan membutuhkan bantuan orang lain. Sehingga manusia dapat menjadi kuat apabila ia telah bersatu dalam sebuah komunitas yang disebut masyarakat. Atas kesadarannya tersebut manusia akhirnya saling bersatu satu sama lainnya, untuk memenuhi kebutuhan hidupnya.

Fakta bahwa Tuhan menciptakan manusia untuk dapat hidup dan sekaligus bertahan hidup hanya dengan bantuan makanan. Dia pun membimbing manusia untuk mendapatkan keinginan alamiahnya tersebut dan menanamkan dalam diri manusia kekuatan yang akan memungkinkannya untuk dapat memperoleh makanan. ${ }^{31}$

${ }^{31}$ Rozenthal, Ibnu Khaldun the Muqaddimah, An Introduction to History, 45 
Dalam cara memperoleh makanan, dalam kebutuhan sehari saja seorang individu masih membutuhkan bantuan orang lain. Contohnya adalah dalam pemenuhan beras/gandum, dari proses barang mentahnya saja hingga matang paling tidak dibutuhkan tiga operasi yaitu menggiling, mengaduk, dan memasak. Dari tiga operasi itu saja dibutuhkan alat-alat yang mengharuskan adanya tukang kayu, tukang besi dan tukang periuk. Dengan demikian dapat diketahui bahwa tanpa kombinasi kekuatan dari sesamanya, seseorang tidak akan mampu memenuhi kebutuhan makanannya. Oleh karena itu, melalui kerjasamalah kebutuhan manusia yang begitu besar tersebut dapat terpenuhi. $^{32}$

Dari uraian Ibnu Khaldun tentang cara memperoleh makanan di atas dapat diketahui bahwa seorang individu tidak akan dapat memenuhi seluruh kebutuhan ekonominya sendiri, melainkan mereka harus bekerjasama. Apa yang dapat dipenuhi dari kerjasama antar individu jauh lebih besar nilai keuntungannya daripada bila dilakukan oleh individu tersebut sendirian. Oleh karena itu kemudian menurut Ibnu Khaldun dibutuhkanlah pembagian kerja (division of labour).

\section{Negara}

Keseluruhan model dinamik yang dinasehatkan oleh Ibnu Khaldun kepada para raja adalah sebagai berikut :

a. Kekuatan kedaulatan (al-mulk) tidak dapat dipertahankan kecuali dengan mengimplementasikan syariah,

${ }^{32}$ Ibid 
b. Syariah tidak dapat diimplementasikan kecuali oleh sebuah kedaulatan (al-mulk),

c. Kedaulatan tak akan memperoleh kekuatan kecuali bila didukung oleh sumber daya manusia (ar-rija $>l)$,

d. Sumber daya manusia tidak dapat dipertahankan kecuali dengan harta benda $(a l-m a>l)$,

e. Harta benda tidak dapat diperoleh kecuali dengan pembangunan (al- 'ima $>r a h)$,

f. Pembangunan tidak dapat dicapai kecuali dengan keadilan ( $a l$ - ' $a d l)$,

g. Keadilan merupakan tolak ukur $(a l-m i>z a>n)$ yang dipakai Allah untuk mengevaluasi manusia dan

h. Kedaulatan mengandung muatan tanggung jawab untuk menegakkan keadilan $\left(a l-{ }^{\prime} a d l\right)$.

Delapan prinsip (kalimat hjikamiyyah) dari kebijaksanaan politik, masing-masing dihubungkan dengan yang lain untuk memperoleh kekuatan, dalam sebuah alur daur di mana permulaan dan akhir tidak dapat dibedakan. ${ }^{33}$

Negara dalam pemikiran Ibnu Khaldun terbentuk pada tahap tertentu dari perkembangan masyarakat. Dalam masyarakat inilah muncul organisasi kemasyarakatan yang menurutnya adalah suatu keharusan bagi ummat manusia. Sebagaimana yang dikemukakan oleh banyak ahli filsafat, manusia adalah mahluk politik atau sosial (zoon politicon). Manusia tidak dapat hidup tanpa organisasi kemasyarakatan

${ }^{33}$ M. Umer Chapra, Masa Depan Ilmu Ekonomi : Sebuah Tinjauan Islam, (Gema Insani Press : Jakarta, 2001), 126 
yang biasa disebut dengan kota atau polis. Manusia diciptakan dalam keadaan akan bertahan hidup dengan bantuan makanan. Untuk memenuhi kebutuhan hidupnya tersebut manusia tidak bisa berdiri sendiri, mereka pasti membutuhkan orang lain. Karena itu keberadaan organisasi masyarakat yang mengatur tentang hubungan antar individu sangat dibutuhkan. ${ }^{34}$

Ibnu Khaldun berpendapat bahwa ada faktor lain pembentuk Negara (Daulah), yaitu 'as\}abiyah. 'As\}abiyah mengandung makna Group Feeling - solidaritas kelompok - fanatisme kesukuan nasionalisme - atau sentimen sosial. Yaitu cinta dan kasih seseorang manusia kepada saudara atau tetangganya ketika salah satu darinya diperlakukan tidak adil atau disakiti. ${ }^{35}$

Akan tetapi hambatan jalan untuk mencapai kedaulatan adalah kemewahan. Karena menurut Ibnu Khaldun semakin besar kemewahan dan kenikmatan maka semakin dekat mereka dengan kehancuran, bukan tambah memperoleh kedaulatan. Kemewahan telah menghancurkan dan melenyapkan solidaritas sosial. Jika suatu negara sudah hancur, maka ia akan digantikan. ${ }^{36}$

Khilafah menurut Khaldun adalah pemerintahan yang berlandaskan agama yang memerintahkan rakyatnya sesuai dengan petunjuk agama baik dalam hal keduniawian atau akhirat. Maka

${ }^{34}$ Fitri, “Konsep Kenegaraan Perspektif Ibnu khaldun” http://ilaelfitri-ilaelfitri.blogspot.com/ 2012/03/ konsep- kenegaraan-perspektif-ibnu.html (17 Desember 2013). Bandingkan dengan Rozenthal, Ibnu Khaldun the Muqaddimah, An Introduction to History, 45-46

${ }^{35}$ Wikipedia, "Teori Siklus Ibnu Khaldun”. Bandingkan dengan Rozenthal, Ibnu Khaldun the Muqaddimah, An Introduction to History, 91

${ }^{36}$ Ibid 
pemerintahan yang dilandaskan pada agama disebut Khilafah, Imamah atau Sulthanah. Sedang pemimpinnya disebut dengan Khalifah, Imam atau Sulthan. Khilafah adalah pengganti Nabi Muhammad SAW dengan tugas mempertahankan agama dan menjalankan kepemimpinan dunia. Lembaga Imamah adalah wajib, dibuktikan dengan dibai'atnya Abu Bakar sebagai Khalifah. Tetapi ada juga yang berpendapat bahwa Imamah wajib dikarenakan adanya akal pada manusia yang memerlukan organisasi sosial. Namun hukum wajibnya adalah fardlu kifa>yah. ${ }^{37}$

Ibnu Khaldun menetapkan 5 syarat bagi Khalifah, Imam, ataupun Sulthan, yaitu : Berilmu, Adil, Cakap (mempunyai kemampuan), Sehat dan panca indera dan badannya

\section{Fungsi Pemerintah}

Seperti telah diuraikan di awal sub bab di atas, bahwa menurut Ibnu Khaldun ada kesalingterkaitan antara syariah $(S)$, pemerintah $(G)$, masyarakat/manusia $(\mathrm{N})$, kekayaan/harta $(\mathrm{W})$, pembangunan (g) dan keadilan (j), kesemua variable tersebut saling mempengaruhi dan dipengaruhi.

Dari beberapa variable di atas, variable pembangunan (g) dan keadilan (j) perlu mendapat perhatian lebih. Pembangunan merupakan unsur penting dalam masyarakat, tanpa pembangunan masyarakat tidak akan maju dan berkembang. Namun, pembangunan tidak akan berarti tanpa keadilan. Oleh karena itu perlu konsep distributive justice untuk mewujudkan keadilan pembangunan tersebut ${ }^{38}$.

\footnotetext{
37 Ibid

${ }^{38}$ Agustianto, “Pemikiran Ekonomi Ibnu Khaldun”
} 
Bila masing-masing variable itu digabung, relasi fungsional terwujud dalam formula $\mathrm{G}=\mathrm{f}(\mathrm{S}, \mathrm{N}, \mathrm{W}, \mathrm{g}$ dan $\mathrm{j})$ atau $\mathrm{G}$ adalah fungsi dari variable (S, N, W, g, dan j). G ditempatkan sebagai variable dependent, karena $\mathrm{G}$ dalam hal ini adalah kelangsungan peradaban, kejayaan atau kemunduran/keruntuhan, dipengaruhi oleh lima variable tersebut. Secara sederhana bisa dibaca bahwa penguasa $(\mathrm{G})$ bertugas dan bertanggungjawab menerapkan syari'ah (S), sebab tanpa syari'ah, masyarakat akan kacau, negara akan runtuh. Negara juga harus menjamin hak-hak masyarakat dan bertanggungjawab mewujudkan kesejahteraan masyarakat $(\mathrm{N})$ agar masyarakat sejahtera/makmur (W), melalui pembangunan (g) yang adil. Bila variable-variable itu tidak dipenuhi, maka kekuasaan tinggal menunggu waktu runtuhnya. ${ }^{39}$

Contoh lainnya adalah keadilan (j). bagaimanapun, keadilan (j) meniscayakan adanya suatu aturan perilaku. Syariah (S) memberikan aturan demikian. Namun tak ada aturan moral yang berjalan efektif kecuali jika hal itu diketahui dengan baik oleh masyarakat dan suatu otoritas politik yang efisien $(\mathrm{G})$ atau $w a>z i$ ' menjamin implementasinya tanpa pandang bulu. ${ }^{40}$ Di dalam Muqaddimah dinyatakan :

The only way to cultivation is through justice. Justice is a balance set up among mankind. The Lord set it up and appointed an overseer for it, and that (overseer) is the ruler. ${ }^{41}$

${ }^{39}$ Ibid

${ }^{40}$ Chapra, Masa Depan Ilmu Ekonomi : Sebuah Tinjauan Islam, 130

${ }^{41}$ Rozenthal, Ibnu Khaldun the Muqaddimah, An Introduction to History, 37 
Volume 01 Nomor 01, Desember 2017

Artinya : Satu-satunya cara untuk perkuatan/persatuan adalah melalui keadilan. Keadilan adalah keseimbangan yang diatur di antara manusia. Tuhan mengatur itu dan menunjuk seorang pengawas untuk itu, dan bahwa (pengawas itu) adalah penguasa/pemimpin.

\section{Tugas Pemerintah}

Menurut Ibnu Khaldun dalam Muqaddimah-nya pemerintah memiliki tugas yang berkaitan dengan masalah ekonomi, diantaranya :

The office of market supervisor (hisbah) is a religious position. It falls under the religious obligation "to command to do good and forbid to do evil," which rests with the person in charge of the affairs of the Muslims. He appoints to the position men whom he considers qualified for it. The obligation thus devolves upon the appointee. He may use other men to help him in his job. He investigates abuses and applies the appropriate punishments and corrective measures. He sees to it that the people act in accord with the publik interest in the town (under his supervision). ${ }^{42}$

Artinya : Kantor pengawas pasar (hisbah) adalah posisi religius. Posisi ini berada di bawah otoritas keagamaan "(berfungsi) untuk memberi perintah agar (masyarakat) berbuat baik dan melarang berbuat jahat," yang bertanggung jawab pada urusan kaum muslimin. Dia menunjuk orang-orang yang cakap bagi posisi tersebut. Kewajiban yang demikian diserahkan pada orang yang ditunjuk tersebut. Dia mungkin menggunakan orang lain untuk membantunya dalam

${ }^{42}$ Ibid, 68 
Volume 01 Nomor 01, Desember 2017

pekerjaannya. Dia menyelidiki pelanggaran dan menerapkan hukuman yang tepat dan langkah-langkah perbaikan. Dia melihat itu bahwa orang-orang bertindak sesuai dengan kepentingan publik/umum di kota tersebut (di bawah pengawasan-Nya).

Di antara tugas dari pemerintah adalah mengawasi pasar, hal itu ditunjukkan dengan adanya lembaga dibawah naungan lembaga kehakiman yang bernama lembaga hisbah. Selain itu Ibnu Khaldun juga menyertakan sebuah lembaga yang berkaitan dengan pengelolaan mata uang yang disebut sebagai mint, di dalam Muqaddimah dinyatakan :

The office of the mint is concerned with the coins used by Muslims in (commercial) transactions, with guarding against possible falsification or substandard quality (clipping) when the number of coins (and not the weight of their metal) is used in transactions, and with all else relating to (monetary matters. $)^{43}$

Artinya : Kantor/lembaga bernama mint yang berkaitan dengan koin yang digunakan oleh umat Islam dalam (komersial) bertransaksi, dengan menjaga terhadap kemungkinan pemalsuan atau kualitas yang tidak memenuhi syarat (potongan) ketika jumlah koin (bukan berat logam mereka) digunakan dalam transaksi, dan dengan semua yang lain yang berkaitan dengan (moneter.)

Ibnu Khaldun juga menjelaskan bahwasanya dalam sebuah pemerintahan diperlukan seorang ahli dalam berbagai bidang penting

${ }^{43}$ Ibid, 68 
Volume 01 Nomor 01, Desember 2017

lingkup pemerintahan, di antaranya adalah sekretaris keuangan. Ibnu Khaldun menjelaskan dalam Muqaddimah-nya sebagai berikut :

Bookkeeping and the ministry (diwan of tax collection) were another, separate rank. The person in charge of it was called Sahib alashghal (Manager of Financial Affairs) He had complete charge of income and expenditures. He audited the finances, collected payments, and punished defaulters. ${ }^{44}$

Artinya : Pembukuan dan kementrian (diwan pemungutan pajak) yang lain, yang terpisah. Orang yang bertanggung jawab atas itu disebut Sahib al-as\}g\}al (Manajer Urusan Keuangan) Dia memiliki komando yang menyeluruh berkaitan dengan pendapatan dan pengeluaran. Dia mengaudit keuangan, kumpulan pembayaran, dan menghukum yang tidak memenuhi kewajiban.

Selanjutnya Ibnu Khaldun juga menjelaskan tentang masalah pajak, menurut Ibnu Khaldun pajak yang tinggi akan menurunkan pendapatan pemerintah karena lesunya perdagangan (akibat pajak yang tinggi), sehingga ketika pemerintah mengalami deficit anggaran mereka tidak sanggup member intensif dan fasilitas untuk kepentingan umum. Ibnu Khaldun menjelaskan dalam Muqaddimah-nya :

when the decrease is noticed, the amounts of individual imposts are increased. This is considered a means of compensating for the decrease. Finally, individual imposts and assessments reach their limit. It would be of no avail to increase them further. The costs of all cultural

${ }^{44}$ Rozenthal, Ibnu Khaldun the Muqaddimah, An Introduction to History, 72 
Volume 01 Nomor 01, Desember 2017

enterprise are now too high, the taxes are too heavy, and the profits anticipated fail to materialize. Thus, the total revenue continues to decrease, while the amounts of individual imposts and assessments continue to increase, because it is believed that such an increase will compensate (for the drop in revenue) in the end. Finally, civilization is destroyed, because the incentive for cultural activity is gone. It is the dynasty that suffers from the situation, because it (is the dynasty that) profits from cultural activity. ${ }^{45}$

Artinya : ketika penurunan terlihat, jumlah pungutan atas individu meningkat. Hal ini dianggap sebagai kompensasi atas penurunan tersebut. Akhirnya, pungutan individu dan beban mereka mencapai batas. Ini akan menjadi sia-sia untuk meningkatkan mereka lebih lanjut. Biaya atas semua usaha perusahaan sekarang terlalu tinggi, pajak yang terlalu berat, dan keuntungan diantisipasi gagal terwujud. Dengan demikian, keseluruhan pendapatan terus menurun, sedangkan jumlah pungutan individu dan beban hidup terus meningkat, karena diyakini bahwa peningkatan semacam itu akan mengkompensasi (untuk penurunan pendapatan) pada akhirnya. Akhirnya, peradaban hancur, karena insentif bagi kegiatan usaha hilang. Ini adalah dinasti yang menderita dikarenakan situasi tersebut, karena keuntungan (hanya akan didapat) dari kegiatan tersebut.

${ }^{45}$ Rozenthal, Ibnu Khaldun the Muqaddimah, An Introduction to History, 116 


\section{E. ANALISIS PEMIKIRAN TENTANG MEKANISME PASAR PRESPEKTIF IBNU KHALDUN}

Mekanisme pasar adalah sebuah sistem yang menentukan terbentuknya harga, yang di dalam prosesnya dapat dipengaruhi oleh berbagai hal di antaranya adalah permintaan \& penawaran, distribusi, kebijakan pemerintah, pekerja, uang, pajak dan keamanan. ${ }^{46}$ Dalam proses mekanisme pasar tersebut diharuskan adanya asas moralitas, antara lain : persaingan yang sehat (fair play), kejujuran (honesty), keterbukaan (transparancy), dan keadilan (justice). ${ }^{47}$

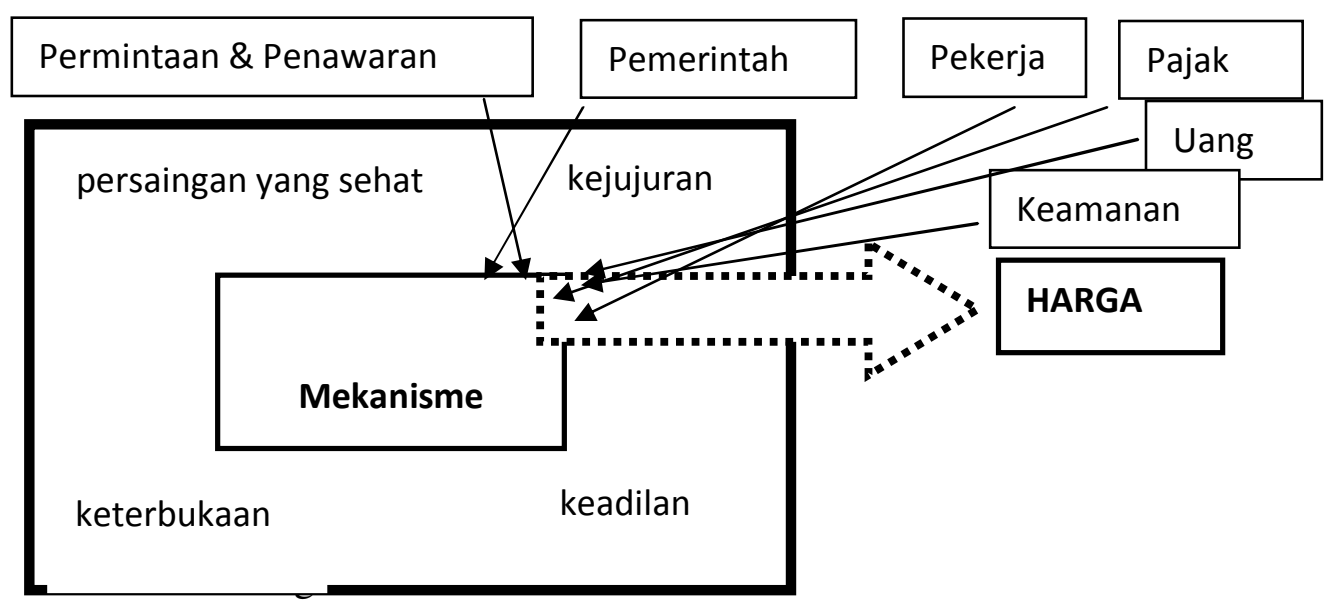

Khaldun dalam Muqaddimah menjelaskan proses terbentuknya harga dalam sebuah komunitas masyarakat. Khaldun menjelaskannya dalam bab 'harga-harga di kota'. Franz Rosenthal yang menterjemahkan

${ }^{46}$ P3EI, Ekonomi Islam , (Jakarta : Rajawali Pers, 2012), 301-345

${ }^{47}$ Ulfa Jamilatul Farida,'Telaah Kritis Pemikiran Ekonomi Islam Terhadap Mekanisme Pasar Dalam Konteks Ekonomi Islam Kekinian' dalam La_Riba-Jurnal Ekonomi Islam, (Sleman:

Universitas Islam Indonesia, 2012), 257-270 
buku Muqaddimah karya Ibnu Khaldun menjadi The Muqaddimah: An Introduction to History, menerjemahkan sebagai berikut:

Then, when a city has a highly developed, abundant civilization and is full of luxuries, there is a verylarge demand for those conveniences and for having as many of them as a personcan expect in view of his situation. This results in a very great shortage of suchthings. Many will bid for them, but they will be in short supply. They will be needed for many purposes, and prosperous people used to luxuries will pay exorbitant prices for them, because they need them more than others. Thus, as one can see, prices come to be high. ${ }^{48}$

Artinya : Sesungguhnya apabila sebuah kota telah makmur dan berkembang serta penuh dengan kemewahan, maka di situ akan timbul permintaan (demand) yang besar terhadap barang-barang. Tiap orang membeli barang-barang mewah itu menurut kesanggupannya. Maka barang-barang menjadi kurang. Jumlah pembeli meningkat, sementara persediaan menjadi sedikit. Sedangkan orang kaya berani membayar dengan harga tinggi untuk barang itu, sebab kebutuhan mereka makin besar. Hal ini akan menyebabkan meningkatnya harga sebagaimana anda lihat.

Khaldun sanggup menjelaskan hubungan sebab-akibat berkembangnya suatu peradaban sebuah komunitas masyarakat terhadap

48

Franz Rozenthal, Ibnu Khaldun the Muqaddimah, An Introduction to History, (London : Routledge \& Kegan Paul, 1958), 283 
harga barang yang mana dalam prosesnya tidak lepas dari adanya fenomena naik dan turunnya permintaan ataupun juga penawaran (supply and demand) atas barang tersebut. Di dalam argument tersebut, Khaldun juga menjelaskan bahwa bila suatu komunitas masyarakat itu berkembang, maka itu akan menyebabkan meningkatnya taraf kemakmuran masyarakat tersebut. Dengan kata lain, Khaldun telah menjelaskan bagaimana proses permintaan dan penawaran dapat mempengaruhi stabilitas harga.

Dalam teks lain Khaldun menjelaskan teori supply and demand dengan lebih rinci, seperti tertulis sebagai berikut :

It should be known that all markets cater to the needs of people. Some of these needs are necessities, foodstuffs, for instance, such as wheat and barley; corresponding foods, such as beans, chick-peas, peas, and otheredible grains; and whole some foods such as onions, garlic, and the like. Other things are conveniencesor luxuries, such as seasonings, fruits, clothes, utensils, mounts, all the crafts, and buildings. When a city is highly developed and has many inhabitants, the prices of necessary foodstuffs and corresponding items are low, and the prices for luxuries, such as seasonings, fruits, and the things that go with them, are high. When the inhabitants of a city are few and its civilization weak, the opposite is the case. ${ }^{49}$

${ }^{49}$ Ibid, 283 
Volume 01 Nomor 01, Desember 2017

Artinya : Ketahuilah bahwa sesungguhnya semua pasar menyediakan kebutuhan manusia, di antaranya kebutuhan (primer), yaitu makanan pokok seperti gandum dan segala jenis makanan pokok lainnya seperti sayur buncis, bawang merah, bawang putih dan sejenisnya. Ada pula kebutuhan yang bersifat (sekunder) dan (tertier) yang merupakan kebutuhan pelengkap seperti bumbu makanan, buahbuahan, pakaian, perabot rumah tangga, kenderaan, dan seluruh produk hasil industri. Apabila sebuah kota berkembang maju dan penduduknya padat (banyak), maka murahlah harga barang kebutuhan (primer) seperti makanan pokok dan menjadi mahal hargaharga barang kebutuhan pelengkap, Apabila penduduk suatu daerah sedikit (seperti desa) dan lemah peradabannya, maka terhadi sebaliknya.(terjadi harga mahal).

Ibnu Khaldun dengan teori supply and demand-nya dapat menjelaskan bagaimana harga itu terbentuk, hingga bagaimana proses terciptanya tingkatan kebutuhan manusia seperti primer, sekunder dan tersier.

Selain dari faktor supply and demand tersebut, Ibnu Khaldun juga menjelaskan faktor lain yang dapat membentuk dan mempengaruhi harga suatu komoditas atau barang yaitu pajak. Dijelaskan bahwa akibat dari adanya pungutan dan pajak atas bea masuk barang ke kota mengakibatkan harga barang di kota menjadi lebih mahal daripada di 
desa. Dari situlah dijelaskan oleh Ibnu Khaldun pengaruh pajak terhadap harga-harga. ${ }^{50}$

Harga terbentuk melalui sebuah mekanisme alamiah. Harga bisa terbentuk akibat dari adanya permintaan atas barang dan juga penawaran. Selain itu, Khaldun menambahkan faktor lain yang dapat mempengaruhi harga barang tersebut yaitu pajak. Sehingga pungutan dan pajak mempunyai peranan yang mampu menjadi pengatur stabilitas harga.

\section{Teori Nilai}

Menurut Ibnu Khaldun di dalam The Muqaddimah: An Introduction to History menyatakan :

A large civilization yields large profits because of the large amount of (available) labor, which is the cause of (profit) $)^{51}$

It will become clear in the fifth chapter, which deals with profit and sustenance, that profit is the value realized from labor. When there is more labor, the value realized from it increases among the (people). Thus, their profit of necessity increases. The prosperity and wealth they enjoy leads them to luxury and the things that go with it, such as splendid houses and clothes, fine vessels and utensils, and the use of servants and mounts. All these (things) involve activities that require their price and skillful people must be chosen to do them and be

\footnotetext{
${ }^{50}$ Ibid, 284
}

${ }^{51}$ Ibid, 287 
incharge of them. As a consequence, industry and the crafts thrive. The income and the expenditure of the city increase. Affluence comes to those who work and produce these things by their labor. ${ }^{52}$

Artinya : Sebuah peradaban besar menghasilkan keuntungan yang besar karena besarnya jumlah (tersedia) tenaga kerja, yang merupakan penyebab dari (keuntungan)

Ini akan menjadi jelas dalam pasal lima, yang berkaitan dengan keuntungan dan rezeki, keuntungan itu adalah nilai yang direalisasikan dari tenaga kerja. Ketika ada lebih banyak tenaga kerja, nilai yang direalisasikannya pun akan turut meningkat. Dengan demikian, keuntungan mereka turut meningkat. Kemakmuran dan kekayaan yang mereka nikmati membawa mereka kepada kemewahan dan hal-hal yang bersamaan dengan itu, seperti rumah-rumah yang indah dan pakaian, pembuluh halus dan peralatan, dan penggunaan pembantu (PRT) dan kendaraan. Semua ini (hal-hal) merupakan kegiatan yang membutuhkan harga/upah dan orang-orang terampil harus dipilih untuk melakukannya dan menjadi ongkos dari mereka. Akibatnya, dunia industri dan kerajinan berkembang. Pendapatan dan pengeluaran kota naik. Kemakmuran datang kepada mereka yang bekerja dan menghasilkan hal-hal ini dengan kerja mereka.

Dari teks di atas, penulis menganalisa bahwa Ibnu Khaldun menitikberatkan tenaga kerja sebagai sumber yang berharga. Khaldun menganggap bahwa tanpa tenaga kerja keuntungan dari akumulasi

${ }^{52}$ Ibid, 280 
modal dan pendapatan tak dapat diraih. Dengan kata lain, Khaldun menilai tenaga kerja sebagai sumber nilai. Kedunya memiliki suatu hubungan yang saling membutuhkan dimana tenaga kerja bisa menciptakan sumber nilai dalam ekonomi pasar dan sumber nilai sendiri tak bisa bertahan tanpa adanya tenaga kerja.

Menurut Ibnu Khaldun, faktor yang paling menentukan dalam struktur perekonomian yang paling penting dan bernilai adalah kerja buruh yang memiliki skills. Mengenai hal tersebut Ibnu Khaldun menjelaskan dalam Muqaddimah-nya :

Some crafts are partly associated with other (crafts). Carpentry and weaving,for instance, are associated with wood and yarn (and the respective crafts needed for their production). However, in the two crafts (first mentioned), the labor (that goes into them) is more important, and its value is greater.

If the profit results from something other than a craft, the value of there sulting profit and acquired (capital) must (also) include the value of the labor by which it was obtained. Without labor, it would not have been acquired. ${ }^{53}$

Artinya : Beberapa kerajinan sebagiannya terkait dengan (kerajinan) yang lain. Pertukangan dan tenun, misalnya, berhubungan dengan kayu dan benang (dan kerajinan masing-masing diperlukan untuk produksi mereka). Namun, dalam dua kerajinan (yang pertama

\footnotetext{
${ }^{53}$ Rozenthal, Ibnu Khaldun the Muqaddimah, An Introduction to History, 298
} 
kali disebutkan), tenaga kerja (yang masuk ke mereka) lebih penting, dan nilainya jauh lebih besar.

Jika hasil keuntungan dari sesuatu selain kerajinan, nilai dari adanya keuntungan itu dan yang diperoleh/dipakai (yaitu modal) harus (juga) mencakup dari nilai tenaga kerja untuk memperolehnya. Tanpa tenaga kerja, itu (kerajinan) tidak akan dapat diperoleh.

Ibnu Khaldun menekankan bahwa usaha dari para pekerja dalam sebuah proses pembuatan kerajinan adalah suatu nilai yang berharga, bahkan nilai tersebut harus ditambahkan pula kedalam biaya produksi karena tanpa buruh/pekerja kerajinan tersebut tak dapat diproduksi. Dengan kata lain, substansi nilai adalah kerja para buruh yang memiliki skill yang mampu memberikan sumber nilai dalam hasil produksi. Itu memang sudah menjadi hubungan kausalitas (sebab-akibat) dalam tatanan perekonomian baik makro ataupun mikro.

\section{Spesialisasi Kerja}

Manusia adalah mahluk yang lemah dan membutuhkan bantuan orang lain. Sehingga manusia dapat menjadi kuat apabila ia telah bersatu dalam sebuah komunitas yang disebut masyarakat. Atas kesadarannya tersebut manusia akhirnya saling bersatu satu sama lainnya, untuk memenuhi kebutuhan hidupnya.

Misalnya, usaha manusia untuk memenuhi kebutuhan pangannya akan membutuhkan setidaknya beberapa proses sebelum makanan tersebut siap dimasak atau dimakan. Seperti pada proses pemenuhan 
akan beras/nasi, setidaknya dibutuhkan petani untuk menanam dan memelihara tanaman padi, dan akan masuk kedalam proses mesin penggiling untuk memanen hasil panen padi dan periuk untuk memasak beras menjadi nasi.

Mengenai hal tersebut, Ibnu Khaldun menjelaskan dalam Muqaddimah-nya :

The reason for this is that, as is known and well established, the individual human being cannot by himself obtain all the necessities of life. All human beings must co-operate to that end in their civilization.

But what is obtained through the co-operation of a group of human beings satisfies the need of a number many times greater (than themselves). For instance, no one, by himself, can obtain the share of the wheat he needs for food. But when six or ten persons, including a smith and a carpenter to make the tools, and others who are in charge of the oxen, the plowing of the soil, the harvesting of the ripe grain, and all the other agricultural activities, undertake to obtain their food and work toward that purpose either separately or collectively and thus obtain through their labor a certain amountof food, (that amount) will be food for a number of people many times their own.The combined labor produces more than the needs and necessities of the workers ${ }^{54}$.

Artinya : Alasan untuk ini adalah bahwa, seperti diketahui pada umumnya, manusia sebagai individu tidak dapat sendirian memperoleh

${ }^{54}$ Ibid, 280 
Volume 01 Nomor 01, Desember 2017

semua kebutuhan hidupnya. Semua manusia harus bekerja sama dengan sesama di dalam peradaban mereka.

Tapi apa yang diperoleh melalui kerjasama sekelompok manusia untuk memenuhi kebutuhannya berjumlah lebih besar (daripada diri mereka sendiri). Misalnya, tidak ada, seseorang yang sendirian, dapat memperoleh bagian dari gandum yang mana ia butuhkan untuk di makan. Tapi ketika enam atau sepuluh orang, termasuk tukang besi dan seorang tukang kayu untuk membuat alat-alat, dan lain-lain yang bertanggung jawab atas lembu, membajak tanah, memanen gandum yang matang, dan semua kegiatan pertanian lainnya, berjanji untuk memperoleh makanan mereka dan bekerja ke arah tujuan itu baik secara terpisah maupun secara kolektif dan dengan demikian diperoleh lah sejumlah makanan melalui kerja mereka, (jumlah itu) akan menjadi makanan untuk sejumlah orang berkali-kali lipat banyaknya dari pada mereka sendiri. Gabungan dari para tenaga kerja memproduksi lebih dari kebutuhan dan kebutuhan para pekerja.

Khaldun menekankan bahwa dibutuhkan kerjasama antar sesama manusia dalam usaha bertahan hidup dan untuk mencapai tujuan dari usaha tersebut maka dibutuhkan pembagian kerja atau spesialisasi dalam berbagai bidang kehidupan.

\section{Negara}

Fungsi negara menurut Khaldun adalah untuk menegakkan hukum pada masyarakat dan menjamin kehidupan yang makmur bagi 
Volume 01 Nomor 01, Desember 2017

masyarakat tersebut, serta menciptakan iklim pembangunan yang merata demi tercapainya keadilan bersama. Fungsi tersebut Khaldun jelaskan melalui sebuah variable interdependen yang oleh Umer Chapra di rumuskan sebagai berikut, $G=f(S, N, W, g$ dan $j)$, kesemua variable tersebut saling mempengaruhi dan dipengaruhi. ${ }^{55}$

Khaldun berpendapat bahwa ada kesalingterkaitan antara negara, masyarakat, kekayaan, hukum maupun pembangunan dan keadilan. Keenam variable tadi saling mempengaruhi dan dipengaruhi. Mengapa demikian? Karena sifat variable tersebut tidak tetap. Apabila salah satu variable bertindak sebagai mekanisme pemicu, maka yang lain dapat bereaksi dalam cara yang sama atau tidak. Jika faktor-faktor yang lain tidak bereaksi pada arah yang sama kerusakan pada salah satu sektor tidak akan merembes pada sektor yang lain dan ini mengakibatkan kemungkinan untuk diperbaiki sektor yang rusak tersebut. Namun, jika sektor-sektor yang lain mengikuti sektor yang menjadi mekanisme pemicu dan bergerak kearah yang berlawanan maka akan sulit teridentifikasi penyebab utama kerusakan system tersebut.

Menurut Ibnu Khaldun dalam Muqaddimah-nya pemerintah memiliki tugas yang berkaitan dengan masalah ekonomi, diantaranya :

The office of market supervisor (hisbah) is a religious position. It falls under the religious obligation "to command to do good and forbid to do evil," which rests with the person in charge of the affairs of the Muslims. He appoints to the position men whom he considers qualified

${ }^{55}$ M. Umer Chapra, Masa Depan Ilmu Ekonomi : Sebuah Tinjauan Islam, (Gema Insani Press : Jakarta, 2001), 126-127 
Volume 01 Nomor 01, Desember 2017

for it. The obligation thus devolves upon the appointee. He may use other men to help him in his job. He investigates abuses and applies the appropriate punishments and corrective measures. He sees to it that the people act in accord with the public interest in the town (under his supervision). ${ }^{56}$

Artinya : Kantor pengawas pasar (hisbah) adalah posisi religius. Posisi ini berada di bawah otoritas keagamaan "(berfungsi) untuk memberi perintah agar (masyarakat) berbuat baik dan melarang berbuat jahat," yang bertanggung jawab pada urusan kaum muslimin. Dia menunjuk orang-orang yang cakap bagi posisi tersebut. Kewajiban yang demikian diserahkan pada orang yang ditunjuk tersebut. Dia mungkin menggunakan orang lain untuk membantunya dalam pekerjaannya. Dia menyelidiki pelanggaran dan menerapkan hukuman yang tepat dan langkah-langkah perbaikan. Dia melihat itu bahwa orang-orang bertindak sesuai dengan kepentingan Publik/umum di kota tersebut (di bawah pengawasan-Nya).

Ibnu Khaldun berpendapat bahwa negara sejatinya bersikap sebagai wasit atau pengadil dalam transaksi ekonomi masyarakatnya dan itu dapat dilihat dari diperlukannya lembaga hisbah yang bertugas untuk mengawasi keadaan dalam pasar sekaligus berhak menjatuhkan hukuman apabila ditengarai terjadi kecurangan didalam pasar.

\footnotetext{
${ }^{56}$ Rozenthal, Ibnu Khaldun the Muqaddimah, An Introduction to History, 68
} 
Volume 01 Nomor 01, Desember 2017

\begin{tabular}{lllllll}
\hline \hline P & $R$ & $O$ & $F$ & I & $T$ & 126
\end{tabular}




\title{
BAB V
}

\section{PENUTUP}

\begin{abstract}
A. Kesimpulan
\end{abstract}
Konsep pemikiran tentang mekanisme pasar khususnya pada faktorfaktor yang mempengaruhinya, Ibnu Khaldun melandaskan bahwa teori harga dalam mekanisme pasar disebabkan oleh adanya hukum permintaan dan penawaran, untuk teori nilai Khaldun melandaskan pada keberadaan buruh/pekerja sekaligus hasil/buah dari pekerjaan mereka, untuk hal spesialisasi kerja Khaldun menjelaskan bahwa itu merupakan sebuah keniscayaan dalam kehidupan masyarakat, dan untuk tugas pemerintah Khaldun menjelaskan bahwa pemerintah bertugas untuk mengawasi pasar demi terciptanya keadilan dan pasar bebas.

menurut Khaldun, kebebasan demi terwujudnya keadilan dalam sebuah mekanisme pasar harus diwujudkan melalui hubungan berantai dari beberapa variable yang saling mempengaruhi dan dipengaruhi diantaranya adalah pemerintah/negara, masyarakat, kekayaan/harta/kemakmuran, syari'ah/hukum dan keadilan, pembangunan. Sedang menurut Smith kebebasan pasar adalah keniscayaan demi terwujudnya keadilan ekonomi bagi masyarakat, yang mana dalam aplikasinya peran pemerintah dalam berekonomi harus direduksi namun dalam hal lain pemerintah wajib menjadi pelindung demi terciptanya keadilan ekonomi 
Volume 01 Nomor 01, Desember 2017

\section{DAFTAR PUSTAKA}

Azwar Adiwarman Karim,Sejarah Pemikiran Ekonomi Islam, Jakarta:

Rajawali Pers, 2010

George Soule, Pemikiran Para Pakar Ekonomi Terkemuka, Yogjakarta :

Kanisius, 1994

Mohammad Abdullah Enan, Life and Work of Ibn Khaldun, Kitab Bhavan :

New Delhi, 1997

Mohamad Hidayat, an Introduction to The Sharia Economic, Jakarta : Zikrul Hakim, 2010

Muhammad Nejatullah Siddiqy, Muslim Economic Thinking, United Kingdom : ICRIEKAAJ and The Islamic Foundation, 1976

Mohammad Abdullah Enan, Life and Work of Ibn Khaldun, Kitab Bhavan :

New Delhi, 1997

Mark Skousen, Sang Maestro"Teori-Teori Ekonomi Modern" : Sejarah

Pemikiran Ekonomi, Jakarta : 2009

Nur Chamid, Jejak Langkah Sejarah Pemikiran Ekonomi Islam, Yogjakarta :

Pustaka Pelajar, 2010

Nur Chamid, Jejak Langkah Sejarah Pemikiran Ekonomi Islam,Jogjakarta :

Pustaka Pelajar, 2010 
Volume 01 Nomor 01, Desember 2017

Sonny Keraf, Pasar Bebas Keadilan \& Peran Pemerintah, Yogjakarta:

Kanisius, 1996

Zainab al-Khundairi, Filsafat Sejarah Ibn Khaldun. Terj. Ahmad Rafi'

Usmani, Bandung: Penerbit Pustaka, 1987

Karim Azwar,Sejarah Pemikiran Ekonomi Islam, 393. Bandingkan dengan,

Abdullah Enan, Life and Work of Ibn Khaldun

M. Umer Chapra, Masa Depan Ilmu Ekonomi : Sebuah Tinjauan Islam, Gema Insani Press : Jakarta, 2001

Wikipedia, “Teori Siklus Ibnu Khaldun”. Bandingkan dengan Rozenthal, Ibnu Khaldun the Muqaddimah, An Introduction to History, 